\title{
Energy Efficient Approach for Survivable WDM Optical Networks
}

\author{
Lena Wosinska, Member, IEEE, A. Jirattigalachote, P. Monti, Member, IEEE \\ "A. Tzanakaki, Senior Member, IEEE, " K. Katrinis \\ The Royal Institute of Technology KTH/ICT, Electrum 229, 16440 Kista, Sweden \\ *Athens Information Technology (AIT), 19.5 Markopoulou Av., P.O. Box 68, 19002 Peania, Greece \\ Tel: (46) 8790 4252,Fax: (46) 8790 9040,e-mail: wosinska@kth.se
}

\section{EXTENDED ABSTRACT}

The traffic volume that needs to be handled by communication networks is growing very fast due to the continuously increasing number of end-users and to the new and emerging services that can be accessed on the Internet. This reflects into a need for increased network capacity, which in turn introduces higher energy consumption of the network infrastructure. In view of the scale of the network of the future, it becomes evident that investigation of technologies, methodologies and approaches that can offer energy savings are of the utmost importance. It is widely accepted that optical network technologies will have a central role in the formation and the support of the network of the future. Therefore, it is important to explore novel solutions with respect to their energy efficiency. Several attempts to reduce power consumption in optical networks can be found in the literature [1-5]. However, so far, no attention is paid to the impact of resilience in the overall network power consumption.

On the other hand, wavelength division multiplexing (WDM) networks consist of very high capacity links and nodes where a single failure may disrupt an enormous number of services. Therefore, backup resources need to be provided for the purpose of survivability. Regardless of the network status, optical amplifiers and switching nodes along the backup paths are always active (i.e. switched on). Moreover, backup paths are typically longer than their respective primary paths, and therefore the total energy consumed by the spare resources in the network may be relatively high.

This paper proposes a novel approach to save energy in survivable optical networks. The approach is based on appropriately handling protection resources, where a trade-off between recovery time and energy consumption is exploited. The proposed idea has been tested through simulations using a Pan-European (COST 239) and Pan-American (NSFNet) network topology. For benchmarking purposes, results for the proposed energy-aware approach are compared against a conventional one, based on shortest path routing. With the proposed approach, more than 40\% energy saving has been observed in case of the COST 239 network and more than $30 \%$ in the NSFNet. To further increase the energy savings in the network, a routing algorithm (specifically tailored for the proposed energy-aware approach) is also presented, showing that an additional $20 \%$ in energy reduction is achievable.

Keywords: Green networks, energy-aware, power efficiency, survivable WDM network protection.

\section{ACKNOWLEDGEMENTS}

The work described in this paper was carried out with the support of the BONE-project ("Building the Future Optical Network in Europe"), a Network of Excellence funded by the European Commission through the 7th ICT-Framework Programme.

\section{REFERENCES}

[1] J. C. C. Restrepo, C. G. Gruber, and C. M. Machuca, "Energy profile aware routing”, in Proc. of IEEE ICC 2009, pp. 1-5, Jun. 2009.

[2] E. Yetginer, and G. N. Rouskas, "Power efficient traffic grooming in optical WDM networks", in Proc. of IEEE GLOBECOM 2009, Nov.-Dec. 2009.

[3] L. Chiaraviglio, M. Mellia, and F. Neri, "Reducing power consumption in backbone networks", in Proc. of IEEE ICC 2009, pp. 1-6, Jun. 2009.

[4] G. Shen and R. Tucker, "Energy-minimized design for IP over WDM networks", J. of Opt. Comm. and Netw., vol. 1, no. 1, Jun. 2009.

[5] M. Pickavet, W. Vereecken, S. Demeyer, P. Audenaert, B. Vermeulen, C. Develder, D. Colle, B. Dhoedt, P. Demeester, "Worldwide energy needs for ICT: The rise of power-aware networking", in Proc. of IEEE ANTS2008, Mumbai, India, Dec. 2008. 